\title{
Authority fairness as contingent on intergroup attitudes: Review and expansion of relational models of procedural justice
}

\section{Karolina Urbanska}

School of Psychology, Queen's University Belfast

Department of Psychology, University of Sheffield

\section{Sam Pehrson}

School of Psychology and Neuroscience, University of St Andrews

Michael J. Platow

Research School of Psychology, Australian National University

Rhiannon N. Turner

School of Psychology, Queen's University Belfast

\section{*** THIS MANUSCRIPT IS CURRENTLY UNDER REVIEW ***}

\section{Author note}

This research was supported by doctoral funding from the Department for Employment and Learning, Northern Ireland and carried out while the first author was at Queen's University Belfast.

Correspondence concerning this article should be addressed to Karolina Urbanska, Department of Psychology, University of Sheffield, Cathedral Court, 1 Vicar Lane, S1 2LT Sheffield. Email: 
AUTHORITY FAIRNESS AND INTERGROUP ATTITUDES

\begin{abstract}
Relational models of procedural justice propose that fair procedures from authorities communicate that one is an affirmed member of the society that they represent. Authorities who use principles of procedural justice are more likely to be seen as legitimate, increasing compliance and cooperation from the public. However, ensuring that authority decisions will be accepted is not necessarily a guaranteed outcome of employing fair procedures. The empirical evidence discussed here questions what drives perceptions of authority fairness and decision acceptance by considering how social identities shape fairness perceptions. We argue that understanding these processes is crucial for authorities dealing with complex intergroup-level mediations. We support these claims by presenting an experimental study conducted in the context of post-conflict relations between Catholics and Protestants in Northern Ireland. We show that people with more negative outgroup attitudes saw restrictive police actions as fairer when these actions targeted the outgroup (versus ingroup), and more strongly preferred for facilitative police decisions concerning the ingroup (versus outgroup). In contrast, people with positive outgroup attitudes did not evaluate police decisions depending on their own community belonging. The findings suggest that the nature of intergroup relations is a relevant element in responses to authority decisions. We outline new directions to theoretical developments of how authorities can effectively serve social systems that they represent.
\end{abstract}

Keywords: procedural justice, fairness, authority, police, intergroup relations, social identity 
AUTHORITY FAIRNESS AND INTERGROUP ATTITUDES

Authority fairness as contingent on intergroup attitudes: Review and expansion of relational models of procedural justice

In December 2012, Belfast City Council, Northern Ireland, voted to fly the British flag at the Belfast City Hall only on specific dates, rather than all year round as it had previously been the case. While Northern Ireland is demographically made up of ethnonational Catholic and Protestant communities, this flag is associated more closely with the Protestant population because of their strong identification with the United Kingdom. Catholics tend not to identify with this flag but rather with the Irish flag. The council's decision was made on the grounds that its continuous presence contradicted the neutrality of the building as a shared space. Protestors, who were mainly Loyalists and of Protestant background, demanded a reversal of this decision. When the protests emerged, Nationalists, who are mainly of Catholic background, criticised police for not handling the protests efficiently as disruptions were caused to the traffic and local businesses. However, the pressure arising from these criticisms led to a change to the police strategy around the handling of the protests. The police became more active and hands-on in ensuring that the protest remained peaceful and that no one caused disruption. This led Loyalist community members to feel that the police were treating protestors harshly, failing to facilitate peaceful protesting (see Nolan et al., 2014 for an in-depth analysis). Effectively, the police were caught between the responses of the two communities with conflicting expectations of what constitutes 'fair' treatment. This dispute raises a crucial but relatively unexplored issue for the social psychology of authority legitimacy: that group membership and the social context in which the group exists may directly contribute to how authority decisions are perceived and made sense of, especially in terms of how fair they are.

The purpose of this article is to discuss how intergroup relations shape individuals' responses to authority decisions. First, we provide a critical theoretical evaluation of the dominant model in this research area, the procedural justice hypothesis, by drawing on 
social identity research in the domain of fairness. Second, we report an experimental study demonstrating that evaluations of authority fairness in relation to decisions made about one's own group and other groups are contingent on intergroup attitudes. This prompts us to conclude that the relationship between authorities and people they serve need to be understood in the wider intergroup context of authority decision-making.

\section{Fairness in authority decisions}

Understanding how authorities such as police and governments can achieve cooperation and compliance from individuals is at the heart of their role. As they do not possess limitless resources, it is likely impossible for the social systems in which these authorities operate to meet the demands of every individual in society. However, an indefinite resource that is consistently linked with attaining police legitimacy is fair and respectful treatment (Tyler, 1997, 2006), a form of procedural justice (Thibaut \& Walker, 1975). Procedural justice places emphasis on both the procedures that are employed during decision-making as well as interpersonal treatment. For example, for the police, procedural fairness would entail having trustworthy motives, being neutral and providing respectful treatment to the individual (Leventhal, 1980; Lind \& Tyler, 1988). Moreover, allowing people voice and acknowledging their opinions, is both normatively procedurally fair and fosters perceptions of procedural justice (Folger, 1977). Procedural justice has been identified as key in fostering positive evaluations of the authorities and their decisions. In an influential study, Sunshine and Tyler (2003) conducted a telephone survey of New York residents in which they evaluated the relative contribution of perceived procedural justice and distributive justice (i.e., whether the resources are distributed fairly) to how police were evaluated. The analysis indicated that perceptions of procedural justice were stronger than distributive fairness and, thus, the primary predictor of perceived police legitimacy: a belief that the police ought to be obeyed even if their decisions are judged to be wrong (French \& Raven, 1959; Tyler, 2006; Tyler \& Huo, 2002). If the police were perceived to employ fair procedures 
in their decision-making, then, overall, they were more likely to be perceived as legitimate. More recent evidence suggests pitting procedural and distributive fairness against one another in predicting decision acceptance could give rise to misleading results. Pehrson, Devaney, Blaylock, and Bryan (2017) report factor analytic evidence that items measuring one aspect of procedural fairness (impartial decision making) and those measuring distributive fairness (equal treatment between groups) in fact tap a common 'impartiality' factor, while items measuring the other main aspect of procedural fairness (interpersonal respect) load separately. Thus, evidence purportedly showing procedural fairness to be more important than distributive fairness is based on an unsupported distinction between impartial decisions and fair treatment of different groups. The importance of fostering perceptions that authorities are fair is especially clear in the case of institutions such as the police or governments that seek compliance from public in order to maintain social order.

The link between procedural justice and positive evaluations of authorities and their decisions has been widely observed in contexts within and outside policing, providing a strong support for the procedural justice hypothesis (Jonathan-Zamir \& Weisburd, 2011; Mazerolle, Bennett, Davis, Sargeant, \& Manning, 2013; Ramirez, 2008; Sugawara \& Huo, 1994; Tyler \& Huo, 2002; Tyler \& Sevier, 2014). Because the procedural justice hypothesis has been dominating the field, several explanatory models have been put forward. One strand of models, referred to as relational models of procedural justice (RMPJs) argue that fair treatment matters because it has implications for people's identities (Tyler, 1997). Early work on RMPJs argued that people do not care about procedural justice simply for instrumental reasons (i.e., because people think that authorities acknowledging their opinions may sway the authorities' decisions; Thibaut \& Walker, 1975). Rather, people care about fair procedures because these serve as symbolic confirmation of their own social standing within relevant groups (Tyler, Degoey, \& Smith, 1996). Studies demonstrate that provision of fair procedures increases perceived fairness of the authorities and their decisions even if this provision has no influence on the final decision making (Hildreth, 
Moore, \& Blader, 2014; Lind, Kanfer, \& Earley, 1990; Platow, Filardo, Troselj, Grace, \& Ryan, 2006). Instead, voice provision communicates that one is a valued member of the group or society and confirms one's social standing in that context. In contrast, procedurally unfair treatment, such as voice denial, conveys exclusion from the group. Critically for our current analysis, receiving or being denied voice contributes to people's perceptions of authorities. People have positive perceptions of authorities when they are treated fairly by the authorities. There is less agreement on whether the importance of having fair procedures to foster positive evaluations of authorities is contingent on the recipients of this fair treatment identifying with the group that the authority represents (e.g., see Ellemers, Rijswijk, Bruins, \& Gilder, 1998) or not (e.g., see Sargeant, Antrobus, Murphy, Bennett, \& Mazerolle, 2014). Nevertheless, there is a general consensus that identification with wider society is relevant for seeing authorities as legitimate and accepting their decisions (Bradford, Murphy, \& Jackson, 2014; see also Bradford, 2014).

Theoretical explanations aside, there is an accumulation of evidence to indicate that the perception of fairness is an important basis for acknowledging authorities as legitimate and, thus, for securing compliance and cooperation with their decisions. This finding notwithstanding, in this paper we argue that fairness depends on people's overall judgements and is not straightforwardly an objective quality in social reality. People perceptions of different types of fairness are often very highly related (Pehrson et al., 2017), so assessing an overall judgement of fairness may better represent how people perceive authorities. Moreover, we argue that these judgements of authority fairness are not made by isolated individuals in a social vacuum but are intrinsically related to their shared social identities, and group memberships (Hauenstein, McGonigle, \& Flinder, 2001; Platow, Wezel, \& Nolan, 2003). This has a range of consequences on how authority decisions are received and, in particularly, whether these decisions are accepted or resisted. Of course, other individual-level factors such the ability to feel empathetic concern certainly matter when evaluations of fairness are made (Urbanska, McKeown, \& Taylor, 2019), but the focus of this 
AUTHORITY FAIRNESS AND INTERGROUP ATTITUDES

article lies in group and intergroup behaviour. To dissect the importance of belonging to social groups on fairness, we next consider how being a part of the group impacts perceptions of fairness.

\section{The group-level analysis of fairness judgements}

Clearly, judgements of procedures as being either fair or unfair lie at the heart of existing RMPJs' analyses of legitimacy. However, these theories have not examined how such judgements are typically made, other than by delineating the various elements required for a decision or encounter to be perceived as fair, such as voice, impartiality and so forth. Although there is no explicit claim that people's fairness judgements reflect an objective level of procedural fairness in the authority's conduct, this is implied in the absence of other explanations as to how such judgements happen. It is assumed that if an authority makes a decision in an impartial way, provides voice opportunities, and treats people with respect, then the authority is fair. Studies manipulating procedural fairness by training police officers to use procedural justice principles certainly assume that it will be perceived as so (e.g., Mazerolle, Bennett, Antrobus, \& Eggins, 2012). In contrast to this, we suggest that fairness judgements should be considered as judgements rather than as objective summaries of procedural fairness criteria. Fairness, then, is not an inventory list on which people can tick off all the boxes. Rather, these judgements are framed in a crucial way by our membership in social groups.

RMPJs do conceptualise individuals' relationships with authorities in terms of social identities and group membership, viewing cooperation with authorities as a function of social identity. Yet, when it comes to the evaluation of fairness itself, the theories remain largely individualistic, dealing with persons' private judgements of their own experiences with authority figures. Authorities do not, however, only interact with one citizen at a time, making these theories prone to ignoring group dynamics (see also Radburn \& Stott, 2018). Even if the decisions are not about groups in general, the authorities may be making decisions 
about individuals, explicitly or implicitly, on the basis of their social group membership. For example, police stopping non-White than White drivers more frequently may produce feelings of racial disparity even if procedural justice principles are used at the interpersonal level (Epp, Maynard-Moody, \& Haider-Markel, 2014). Despite stopping drivers as individuals, through disproportionate selection, authorities are communicating that non-Whites are perceived as a suspect group. Observing injustice done to others may be just as powerful in shaping perceptions of authority, and the subsequent future compliance, as experiencing the injustice personally. This would occur through the process of self-categorising as the member of the same group as the victim of the authority injustice, so that the victims of injustice become a part of one's self-concept. In this way, the injustice done to others becomes an injustice done to oneself (Turner, Hogg, Oakes, Reicher, \& Wetherell, 1987). This self-categorical process dovetails and expands upon Skarlicki and Kulik's (2004) selfinterest motive, whereby people care about the injustice done to others to the extent that it may happen to them. Categorisation processes also mean that individuals may fail to identify with some other social groups and thus process how those groups are treated differently to how they themselves are treated.

Having acknowledged the multi-group structure of societies that authorities represent, one must consider how identification with those groups may influence judgements of authority fairness. According to Platow and O'Brien (2009), it is groups affected by decision-making who agree upon rules and dynamics of fairness. Thus, different groups may not share an understanding of what is fair and legitimate conduct, making the subjective quality of fairness judgments crucial to the way the dynamics of legitimacy unfold. Further evidence demonstrates that groups actively manipulate fairness norms in a way that is beneficial to their own group (Platow, Hunter, Branscombe \& Grace, 2014). Similarly, in the context of mergers between groups, people favour the pattern of the merging of their organisations that would benefit their immediate subgroup's social status (Giessner, Viki, Otten, Terry, \& Tauber, 2006). While in both examples, the participants were deciding on the 
rules associated with distributive justice and not procedural justice, this argument (i.e., that people understand fairness in ethnocentric ways) has also been proposed in terms of procedural justice (Platow, Reid, \& Andrew, 1998). Thus, decisions made in an unfair way are more likely to be perceived as fair if they are favouring an ingroup member in comparison to the same decision regarding an unaffiliated individual.

Evidence suggests that group members place greater weight on collective outcome favourability than procedural fairness when they respond to group-level authority decisions (Leung, Tong, \& Lind, 2007). This highlights that support for group-level authority decisions is likely to be driven by the group's self-interest (see also Peate et al., 2008). More interestingly, while sometimes the group members rejected the new government policies in Leung and colleagues' (2007) study, presumably because of the disservice those decisions did to their group, this had no bearing on how the government as an authority was evaluated overall. This suggests that authority legitimacy and the decisions they make can be evaluated independently. As such, Leung and colleagues highlight a crucial point: groups are driven by the favourability of the outcomes and this can impact on the relative importance of fair procedures in reactions to these decisions. In other words, the same decision can be evaluated as fair by Group A if it serves them well, while Group B may evaluate it as unfair if it does not serve them (see also Platow, Hoar, Reid, \& Harley, 1997; van Prooijen \& Zwenk, 2009; Visschers \& Siegrist, 2012). While having legitimacy may be a protective factor for authorities when they make decisions that are disfavouring to individuals, this has not been tested in contexts when the decision is directly disfavouring group members' ingroup, where group interests may be higher than individual interests. By focusing on the fair procedures and not the outcomes, the RMPJ's understanding of how we react to authority decisions may make them inadequate to explain how groups function in this regard: how outcomes are distributed is pivotal for determining boundaries of social groups (Platow, Grace, Wilson, Burton, \& Wilson, 2008). For this reason, there is a need to 
AUTHORITY FAIRNESS AND INTERGROUP ATTITUDES

integrate theories dealing with responses to authority decisions with social psychological theories of group and intergroup behaviour.

\section{The intergroup context of fairness judgements}

The focus of the present research lies in intergroup-level analysis. Previous research has not, to our knowledge, assessed the direct impact of intergroup relations on responses to authority decisions, thereby ignoring the context in which authority decisions are made. The nature of intergroup interactions has indeed been ignored in the procedural justice research concerning authorities (Radburn \& Stott, 2018). Given that people care about authority fairness aimed at them and those they identify with (but perhaps to the lesser extent with those they do not identify with), the relationship between authorities and subordinates must be conceived as a multipartite one, with an authority serving more than just a homogenous group of individuals (Wenzel \& Jobling, 2006). Multi-group relations identifying as members of some social groups but not others -- thus, characterise the reality in which most encounters with authorities unfold. In this way, authorities banning plastic rarely receive individual response from one citizen at a time. Instead, such decision may serve well parts of the community such as those identifying with other climate change activists as they accommodate a value core to their identity: protection of the environment. On the other hand, if one does not identify with the climate change movement, but instead identifies strongly with other McDonald's milkshake lovers, they would not be served by this decision to the same extent, especially if they are given paper straws as an alternative with the paper disintegrating in their favourite choice of beverage. Considering that authority decisions are not always directly favouring or disfavouring if they do not involve physical resource distribution, it is useful to think about them as either facilitative or restrictive to the groups. Some authority decisions allow groups to express their behaviours, pursue their goals, and ultimately grow while some authority decisions do the opposite: they confine the expression of group behaviour, making it harder for groups to realise their potential. A single 
decision can be facilitative for some groups and restrictive for others so that different groups can relate to these decisions in distinct ways. What has been missing from the analyses, however, is an investigation of how the nature of the relationships between those groups may impact their reactions to authority decisions.

It is widely accepted that the way people perceive their own and other groups is not symmetric. For example, people tend to assume that their own and own group's actions are fairer than others (Boldizar \& Messick, 1988; Messick, Bloom, Boldizar, \& Samuelson, 1985). In addition, the literature suggests that people are more lenient in judgements about the ingroup wrongdoing in comparison to the outgroup (Halabi, Statman, \& Dovidio, 2015) and they may even enjoy disfavouring treatment to the outgroup (Leach \& Spears, 2009). In line with social identity theory, information about own group membership is, in part, derived from other groups, with group members seeking a relatively favourable sanding compared to salient out-groups (Tajfel \& Turner, 1979; Turner, 1975; Turner et al., 1987). For this reason, people's own experiences are not only derived from objective perceptions of, for example, how successful their groups are, but are often done in comparison to other groups. Depending on whether these target comparison groups are considered to be better off or worse off than one's own, feelings of relative deprivation or relative gratification may arise (Davis, 1959; Walker \& Pettigrew, 1984). In the same way, people do not make judgements of fairness in isolation to the social context, but primarily by comparing how they are treated and what they are entitled to in comparison to other groups; group members may feel that they are either better off or worse off in relation to others. This comparison can take place either at interpersonal and intergroup levels, or both (Runciman, 1966). The wealth of literature on group relative deprivation suggests that perceiving injustice toward one's own group is related to negative outgroup attitudes (Dubé \& Guimond, 1986; Guimond \& Dambrun, 2002; Pettigrew et al., 2008). Thus, the subjective feeling that other groups experience relative prosperity in the way they are treated and the resentment towards them appear to fuel one another. 
The nature of relations between groups is therefore essential to understanding people's fairness judgements. It is not simply that people strive to positively differentiate their groups from relevant others, but that the neutral, promotive, or competitive relationships intervene and moderate the psychological processes that affect fairness judgements. In the present article, we wish to demonstrate how positive versus negative intergroup relations may influence how group members respond to authority decisions. Specifically, we ask: "Does the nature of intergroup relations influence the extent to which people accept the decisions authority make about them beyond whether these outcomes are favouring or disfavouring for the group?" There is some initial evidence that this could be the case. Radburn and colleagues (2016) showed that the same restrictive and antagonistic treatment by the police was perceived to be more unfair if it was committed against ingroup members than if it was committed against outgroup members. While these authors did not explicitly measure attitudes towards the outgroup, the nature of the intergroup relations in their research was rather competitive (they were rival football club supporters). For this reason, it is not clear whether warmer intergroup relations would reproduce the patterns of findings reported or whether they would reduce the relative preference for the restrictive treatment of the outgroup in contrast to the ingroup. Understanding how the nature of intergroup relations fuels responses to authority decisions is at the heart of what authority is set out to achieve. Authorities are frequently having to manage competing claims and rights of different groups and attempt to balance them against each other (see Peate, Platow, \& Eggins, 2008). However, the conditions under which authorities can expect more converging responses to their actions across social groups are not clear. Taking into the account the wider context in which authorities can grant compliance and effectively represent all groups in the society is essential for theory development. We address this gap in the theory by considering the role of intergroup relations on perceptions of authority decisions.

\section{The present research: Context and aims}


The present study was conducted in post-conflict Northern Ireland. The conflict, ethno-national in its nature, was a source of animosity between Catholic and Protestant communities. While largely peaceful, Northern Ireland is still a country that is far from being politically stable, with schooling and housing still largely segregated and communities having distinct cultural identities (McVeigh \& Rolston, 2007; Whyte, 1991). One way of enacting community's identity is through parading (Shayegh, Drury, \& Stevenson, 2017). Parades in Northern Ireland are common; for example, in 2014/15, there were almost 5,000 parades of which around $10 \%$ were flagged as highly sensitive (The Parades Commission, 2015). These parades are regarded as contentious due to their routes or paramilitary symbol displays, and calls to modify them are ongoing. Moreover, some of the parades are culturally Protestant, such as the Twelfth parade, taking place on 12th July, honouring the Battle of the Boyne. In contrast, some parades are culturally Catholic. An example of this is Saint Patrick's parade, celebrated on 17th March to commemorate Saint Patrick, the patron of Ireland. Although Saint Patrick's Day now tends to be portrayed as an inclusive day for all communities, up to the early 2000 s it was restricted to Irish nationalist/Catholic areas in Northern Ireland. Admittedly, these two parades are not equal in terms of their exclusiveness as some Protestants and people around the world celebrate Saint Patrick's Day, yet the Twelfth tends to be mainly celebrated exclusively by the Protestant community. However, during both celebrations, flags are widely exhibited: the Union Jack at the Twelfth and the Irish Tricolour at the St Patrick's Day. Display of flags is still a contentious issue in Northern Ireland (Nolan \& Bryan, 2016); flags thus signal the ownership of one community of those particular parades. Having Catholic and Protestant parades within Northern Ireland creates a context whereby police are actively involved in monitoring large social gatherings which celebrate the cultural roots of either an ingroup community or an outgroup community.

Aiming to replicate previous research regarding the importance of outcome favourability for groups (Leung et al., 2007; Radburn et al., 2016), it was expected that decisions that are more favourable to the ingroup will be accepted and deemed fairer than 
decisions that are less favourable. Because we are not interested in simple resource distribution between groups, we operationalise the favourability of decision by manipulating whether the way authority is treating the target group in a way that facilitates or restricts their group behaviour. In other words, we vary authority treatment either as allowing group members to express their group behaviour freely by participating in the celebrations or as policing their behaviour in a way that restricts their participation in the celebrations.

In terms of our hypotheses, our primary prediction was that perceptions of intergroup relations (measured as attitudes towards the other community) would moderate the perceived fairness and decision acceptance of authority decisions for decisions concerning ingroup versus the same decision concerning the outgroup. It was expected that negative outgroup attitudes would be related to the preference of restrictive treatment of authorities towards the outgroup (versus the same decision made for the ingroup) and a stronger preference towards ingroup facilitating decisions than positive outgroup attitudes. Support for this hypothesis would demonstrate that the way people come to accept or reject authority decisions is shaped, at least in part, by the context in which groups function. Furthermore, we expected that these effects would occur while controlling for judgements of police legitimacy. Deriving hypotheses from the police legitimacy literature, one may expect higher police legitimacy levels to be associated with less in-group-favouring judgements of acceptance and fairness by evaluating ingroups and outgroups more similarly. Since legitimacy is more stable than responses to the decisions made by the authority (Leung et al., 2007), we do not expect it to fluctuate depending on whether the decision is made towards the ingroup or outgroup. Finally, in terms of social identification strength, we include it as a further predictor of how groups react to decisions made in relation to their own group versus the outgroup. While this is a secondary analysis, we expect that higher social identification may increase preference for facilitative decisions when they are made in relation to the outgroup: they would be judged as fairer and more likely to be accepted. However, we expect that outgroup attitudes which capture the nature of intergroup relations 
AUTHORITY FAIRNESS AND INTERGROUP ATTITUDES

would still be a primary predictor of how people respond to ingroup versus outgroup decisions based on whether they are facilitative or restrictive.

\section{Methods}

\section{Participants}

Participants of Catholic $(n=83)$ and Protestant $(n=90)$ background from Northern Ireland aged 27 on average $(S D=10.85)$ were recruited via social media and community organisations. Sixty percent were female and $40 \%$ were male. Almost equal proportions of the sample reported being of Catholic and Protestant background (48\% Catholic, 52\% Protestant) and they originally came from a similar proportion of segregated or mixed areas (Protestants: 77\% from predominantly Protestant areas, 5\% from predominantly Catholic areas, $18 \%$ from mixed areas; Catholics: $71 \%$ from predominantly Catholic areas, $8 \%$ from predominantly Protestant areas, 21\% from mixed areas). They participated for either course credit or for a raffle draw of two vouchers worth $£ 30$ and $£ 20$.

\section{Design and procedures}

The study employed a 2 (Target Group: ingroup versus outgroup; between groups) x 2 (Police Treatment: facilitative versus restrictive; within groups) mixed design. Data collection took place online in April 2016 during a time free of contentious parades. The survey took 15 minutes to complete. Ethical approval was received from Psychology Research Ethics Committee at Queen's University Belfast. While it was our intention to make the data openly available, participants were informed that the data will not be shared unless it was requested. In line with this, data will be shared with individual researchers as long as it is not shared online to comply with the information provided to participants at the time. Beyond the measures reported below, we collected some additional measures. All materials including unreported measures are reported in the supplementary materials. 
Target group manipulation. Participants were randomly assigned to either ingroupor outgroup-based scenarios regarding one of the two parades: either The Twelfth parade as a typically Protestant parade or the St Patrick's Day as a typically Catholic parade.

Decision outcome manipulation. Participants read descriptions of two ways of handling the parade they were assigned to, by the patrolling police, displayed in a random order. Efforts were made to match the "unfairness" of both decisions, in one case being too lenient and in another, being too harsh. For this reason, we expected no significant difference in how fairly these decisions are perceived to be handled. One description facilitated the parade attendees, allowing them to consume alcohol on the streets and overlooking the antisocial behaviour:

It was 12th July/St Patrick's. This day is one of the busiest days for the police in the entire year. Their role is to facilitate the celebrations and ensure they run smoothly. This year, as the celebrations began, the police were present at the outskirts of the event. They sat in their vans in some of the side streets, making sure that there is no one around who may cause disorder to the events. There were a lot of intoxicated people around who continued to drink on the street, but everyone was having fun. There were a few arrests made: a few people who opposed the parade taking place and wanting to disrupt it. The next day, the police statement praised the organisers for peaceful celebrations and condemned the behaviour of trouble-makers. However, some comments appeared on social media about how police were tip-toeing around the parade and did not discipline any heavy drinkers who misbehaved.

On the other hand, the second description restricted the parade attendees; the

heavily armed police strictly applied the law to all those who were drinking and misbehaving, condemning their behaviour:

It was 12th July/St Patrick's. This day is one of the busiest days for the police in the entire year. Their role is to facilitate the celebrations and ensure they run smoothly. This year, the police expected a lot of trouble happening as the parade was contentious and provoking for some people. The police showed up heavily armed and remained close to the celebrations at all times, trying to identify anyone causing disorder from both inside and outside. Some people were already heavily intoxicated, but they continued to drink on the street. The police seized as many bottles of drinks as possible because drinking in public is against the law. They also arrested some people who were taking part in celebrations for antisocial behaviour. The next day, the police statement condemned the disruptive behaviour taking place at the 
parade. Comments appeared on social media about how police were too harsh and targeted those celebrating rather than people who were opposing the parade and tried to interrupt it.

Perceived fairness and decision acceptance. Given the recent evidence suggesting that there is little support for the typically assumed factor distinction between procedural and distributive justice and that both procedural and distributive justice contribute to judgements of impartiality (Pehrson et al., 2017), we measured overall fairness.. Participants judged the fairness of the police parade handling via one item 'I think the decisions about handling this parade were fair' on a five-point scale ( 1 = strongly disagree; 5 = strongly agree). To measure decision acceptance, participants responded to two further items: 'I accept the decisions made about handling this parade' and 'I agree with the decisions made about handling this parade' on the same five-point scale. Higher scores indicated higher agreement with a decision (the internal reliability between those two items was high, $r=.90)$.

A score reflecting the difference between facilitative and restrictive decisions was calculated to measure the extent to which individuals preferred facilitative decisions over restrictive decisions (or vice-versa), eliminating individual-level differences. Consequently, a score of zero indicated appraising both decisions as the same in terms of perceived fairness and a positive score indicated appraising facilitating decision as fairer while a negative score suggested perceiving restrictive decision as fairer. These variables are referred to as relative perceived fairness and relative decision acceptance respectively and they act as dependent variables in moderation analyses.

Outgroup attitudes. Outgroup attitudes were measured using Haddock, Zanna, and Esses' (1993) feeling thermometer. Participants indicated their overall attitude towards the other community on an 11-point scale $(0=$ extremely unfavourable, $10=$ extremely favourable). A higher score indicated more favourable outgroup attitudes. 
AUTHORITY FAIRNESS AND INTERGROUP ATTITUDES

Social identification strength. Participants' identification with their own community was measured using Doosje, Ellemers, and Spears' (1995) scale. Participants responded to four items such as 'I identify myself with other Catholic/Protestant people' on a five-point Likert scale $(1=$ strongly disagree; $5=$ strongly agree $)$. Higher scores indicated higher identification with one's own community $(\alpha=.90)$.

Police legitimacy. A scale from Reisig, Bratton, and Gertz (2007) was used to assess police legitimacy. Participants responded to seven items such as 'You should accept police decisions even if you think they are wrong' and 'Disobeying the police is hardly ever justified' on a five-point Likert scale ( $1=$ strongly disagree; $5=$ strongly agree $)$. Higher scores indicated higher perceived legitimacy $(\alpha=.78)$.

\section{Results}

Zero-order correlations are reported in Table 1. While outgroup attitudes and identification strength were not linked to perceived fairness or decision acceptance of facilitating or restrictive police decisions, higher perceptions of police legitimacy were related to perceiving restrictive decisions as fairer, $r(169)=.20, p=.007$, and higher levels of acceptance, $r(170)=.21, p=.006$. Police legitimacy, however, was not associated with responses to facilitating decisions. Thus, judgements of police legitimacy appear to be particularly pertinent to accepting decisions that may be perceived as restrictive and heavy handed towards the group in question. Breaking down this correlation by target group (ingroup, outgroup), the relationship between police legitimacy and perceived fairness of restrictive decisions and decision acceptance of restrictive decisions was stronger for ingroup decisions, $r(79)=.29, p=.010$ and $r(79)=.26, p=.021$, respectively, than the same decisions are aimed at the outgroup, $r(89)=.21, p=.050$ and $r(90)=.20, p=.052$ respectively. The relationship between authority legitimacy and perceptions of restrictive authority decisions was marginally significant. 
Table 1

Zero-order correlations

\begin{tabular}{lccccccc} 
& $\mathbf{1}$ & $\mathbf{2}$ & $\mathbf{3}$ & $\mathbf{4}$ & $\mathbf{5}$ & $\mathbf{6}$ & $\mathbf{7}$ \\
\hline 1. Fairness (F) & - & -.09 & $.86^{* * *}$ & -.04 & .11 & -.06 & .02 \\
2. Fairness (R) & & - & -.11 & $.86^{* * *}$ & .04 & -.04 & $.20^{* *}$ \\
3. Decision acceptance (F) & & & - & -.02 & .09 & -.08 & .05 \\
4. Decision acceptance (R) & & & & - & .04 & -.02 & $.21^{* *}$ \\
5. Outgroup attitudes & & & & & - & -.13 & $.18^{*}$ \\
6. Identification strength & & & & & & - & .04 \\
7. Police legitimacy & & & & & & & - \\
\hline
\end{tabular}

Note. ${ }^{*} p<.05,{ }^{* *} p<.01,{ }^{* * *} p<.001 ; F=$ Facilitative decision, $R=$ Restrictive decision.

\section{Perceived fairness and decision acceptance of facilitative and restrictive decisions}

Two mixed ANOVAs were conducted to evaluate how decisions aimed at ingroup and outgroup (between-subjects factor) were perceived in terms of their fairness (first ANOVA model) and decision acceptance (second ANOVA model) for facilitative versus restrictive authority decisions (within-subjects factor). Firstly, we checked whether there was a significant difference in the perceived fairness of facilitative and restrictive decisions across both community groups. In contrast to our expectations, the restrictive decisions were perceived overall as fairer $(M=3.50, S D=1.02)$ than the facilitating decisions $(M=3.08, S D$ $=1.11), F(1,168)=12.47, p<.001$, partial $\eta^{2}=.07$.

In both ANOVA models, Target Group (ingroup vs outgroup) x Decision (facilitative vs restrictive) interaction on perceived fairness and decision acceptance were significant, $F(1,168)=26.87, p<.001$, partial $\eta^{2}=.14$ and $F(1,168)=22.81, p<.001$, partial $\eta^{2}=.12$, respectively. To break down these interactions, we carried out a series of t-tests, applying a Bonferroni alpha correction. As illustrated by Figure 1, participants deemed the facilitative treatment of their ingroup as fairer $(M=3.34, S D=1.05)$ than the same facilitative treatment of the outgroup $(M=2.62, S D=1.20), t(170)=4.21, p<.001, d=.75$. The same pattern was observed for the decision acceptance whereby participants accepted the facilitative 
treatment towards the ingroup $(M=3.49, S D=.99)$ more than the same treatment towards the outgroup $(M=2.71, \mathrm{SD}=1.10), t(170)=4.90, p<.001, d=.75$. Therefore, a general pattern of ingroup favouritism was observed whereby facilitative decisions were seen as fairer and were accepted more if they were directed at the ingroup.

Participants also perceived decisions restricting the ingroup as less fair ( $M=3.15$, $S D=1.09)$ than the same restrictive treatment towards the outgroup $(M=3.68, S D=1.08)$, $t(168)=-3.17, p=.002, d=-.49$, but there was no significant difference in the extent to which they accepted these decisions, $t(169)=1.81, p=.071, d=-.28$.

(a) Perceived fairness

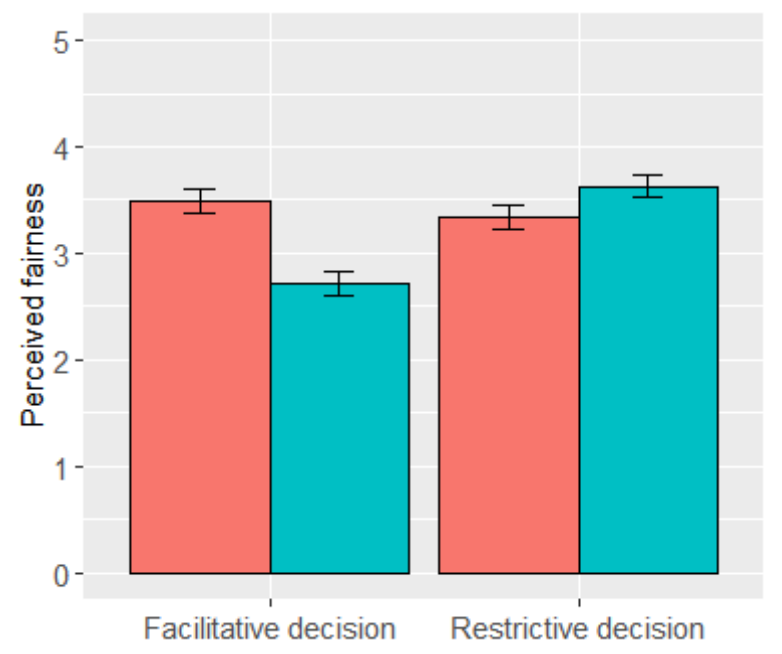

(b) Decision acceptance

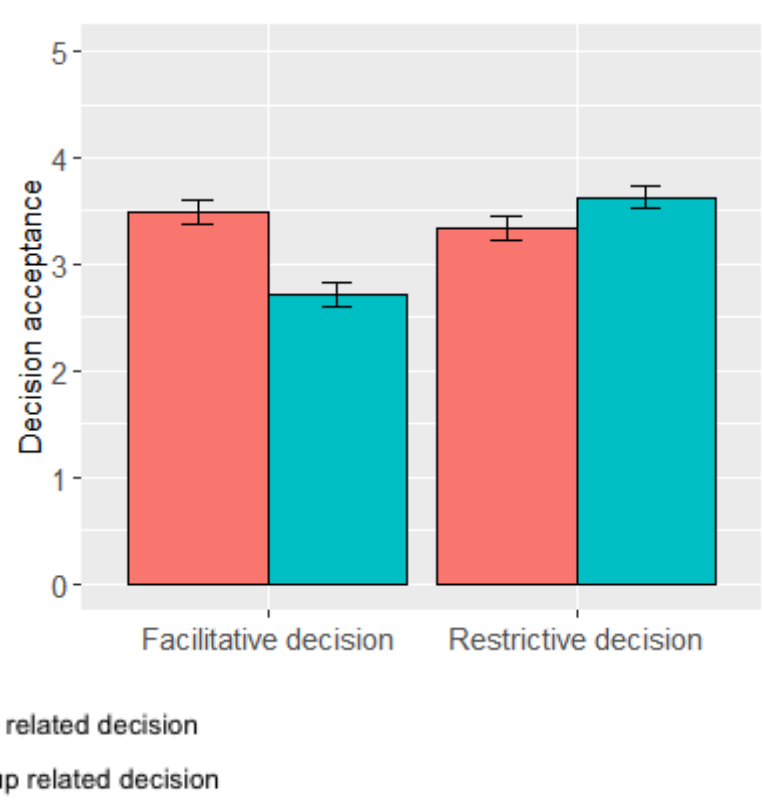

Figure 1. Mean (a) perceived fairness and (b) decision acceptance scores of facilitative and restrictive decisions made in relation to the ingroup or the outgroup. Error bars represent the standard error. 


\section{The role of outgroup attitudes}

To test our primary hypothesis on the role of outgroup attitudes in predicting responses to facilitative and restrictive authority decisions directed at ingroup versus outgroup, we first entered these variables along with social identification strength and police legitimacy into a linear regression model predicting relative perceived fairness as well as relative decision acceptance. Both models were statistically significant and predicted around a fifth of variance, $F(6,168)=9.59, p<.001$, adjusted $\mathrm{R}^{2}=.24$ and $F(6,168)=7.68, p<$ .001 , adjusted $R^{2}=.19$, respectively (see Table 2 ). In line with previously reported results, whether decision was about an ingroup or an outgroup was related to how people responded to facilitative relative to restrictive decisions; there was a higher preference for restrictive handling of the parade over facilitative handling of the parade when the outgroup was the target, $\beta=-1.23, t=3.36, p=.001$, and the more they were accepted, $\beta=-1.16, t=$ 3.06, $p=.003$. Higher police legitimacy, on the other hand, was related to judging restrictive decisions as fairer than facilitative decisions, $\beta=-.16, t=-2.29, p=.023$ but it was not associated with the relative decision acceptance, $\beta=-.13, t=-1.78, p=.077$. In line with the reported cross-correlations, social identification strength was a non-significant predictor of relative perceived fairness and relative decision acceptance, $\beta=.20, t=.93, p=.352$ and $\beta=$ $.14, t=.64, p=.525$, respectively. Nor was the effect qualified by the Identification Strength $\mathrm{x}$ Target group interaction, $\beta=-.28, t=.90, p=.371$ and $\beta=-.24, t=-.74, p=.461$, respectively. Finally, in line with our expectations, the main effect of outgroup attitudes was significant and further qualified by target group interaction for both relative perceived fairness and relative decision acceptance. We used the PROCESS Model 1 template and biascorrected bootstrapped $(n=10,000) 95 \%$ confidence intervals to break down these interactions (Hayes, 2012). 
Table 2

Regression models predicting relative perceived fairness and relative decision acceptance

\section{Relative perceived fairness Relative decision acceptance}

\begin{tabular}{|c|c|c|c|c|c|c|}
\hline & $\beta$ & $\mathrm{t}$ & Adjusted $\mathrm{R}^{2}$ & $\beta$ & $\mathrm{t}$ & Adjusted $\mathrm{R}^{2}$ \\
\hline Target group (Ingroup vs Outgroup) & -1.23 & $-3.36^{* *}$ & 23.5 & -1.16 & $-3.06^{* *}$ & 19.3 \\
\hline Outgroup attitudes & -.89 & $-3.60^{\star \star \star}$ & & -.83 & $-3.24^{* *}$ & \\
\hline Identification strength & .20 & .93 & & .14 & .64 & \\
\hline Legitimacy & -.16 & $-2.29^{\star}$ & & -.13 & -1.78 & \\
\hline Outgroup attitudes x Target group & 1.37 & $3.94^{* * *}$ & & 1.28 & $3.53^{\star *}$ & \\
\hline Identification strength $\times$ Target group & -.28 & -.90 & & -.24 & -.74 & \\
\hline
\end{tabular}

Outgroup attitudes scores were first entered into the moderation model predicting relative perceived fairness across ingroup (coded as 0 ) and outgroup decisions (coded as 1 ). The overall model was statistically significant, $F(3,165)=16.88, p<.001, R^{2}=.23$. In line with the analyses above, there was a higher preference for restrictive handling of the parade over facilitative handling of the parade when the outgroup was the target, $b=-5.09$, se $=.90$, $p<.001,95 \% \mathrm{Cl}[-6.87,-3.31]$. This effect was further qualified by Target Group x Outgroup Attitudes interaction, $b=.49$, se $=.11, p<.001,95 \% \mathrm{Cl}[.27, .71]$ (see Figure 2a). Less positive outgroup attitudes were related to perceiving restrictive decisions as fairer than facilitative decisions when it concerned an outgroup, $b=.19$, se $=.07, p=.006,95 \% \mathrm{Cl}[.05$, .32], but perceiving facilitative decisions as fairer than restrictive decisions when it concerned an ingroup, $b=-.30$, se $=.09, p=.001,95 \% \mathrm{Cl}[-.48,-.12]$. Remarkably, when outgroup attitudes were more positive, there was no difference in relative perceived fairness of ingroup and outgroup decisions, $b=-.25$, se $=.33, p=.433,95 \% \mathrm{Cl}[-.91, .39]$. This was not the case when outgroup attitudes were average, $b=-1.30$, se $=.23, p<.001,95 \% \mathrm{Cl}[-$ 1.76, -.85] or less positive, $b=-2.35$, se $=.36, p<.001,95 \% \mathrm{Cl}[-3.01,-1.69]$; in both cases, facilitative decisions were judged as fairer when they concerned the ingroup than when they concerned the outgroup. 
Entering these variables to a model predicting relative decision acceptance yielded very similar patterns (see Figure $2 b$ ). This model explained $20 \%$ of the variance, $F(3,165)=$ 14.06, $p<.001$ with target group, $b=-4.24$, se $=.82, p<.001,95 \% \mathrm{Cl}[-5.88,-2.61]$, outgroup attitudes, $b=-.66$, se $=.18, p<.001,95 \% \mathrm{Cl}[-1.01,-.31]$, and the interaction between the two, $b=.40$, se $=.10, p<.001,95 \% \mathrm{Cl}[.20, .61]$, predicting relative decision acceptance, all in the same directions.

(a) Perceived fairness

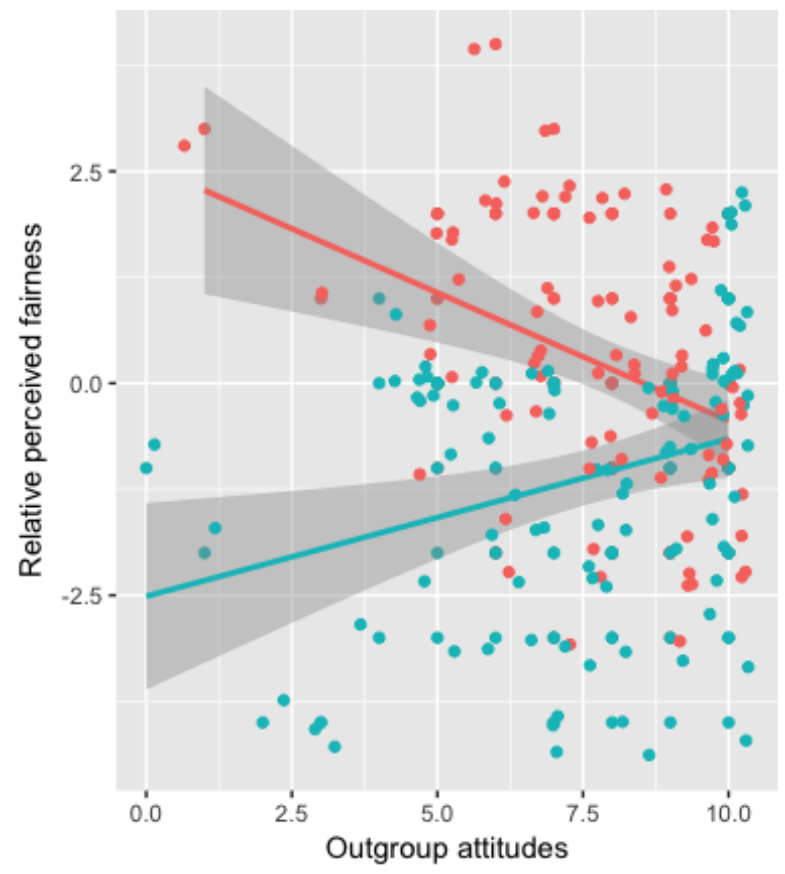

(b) Decision acceptance

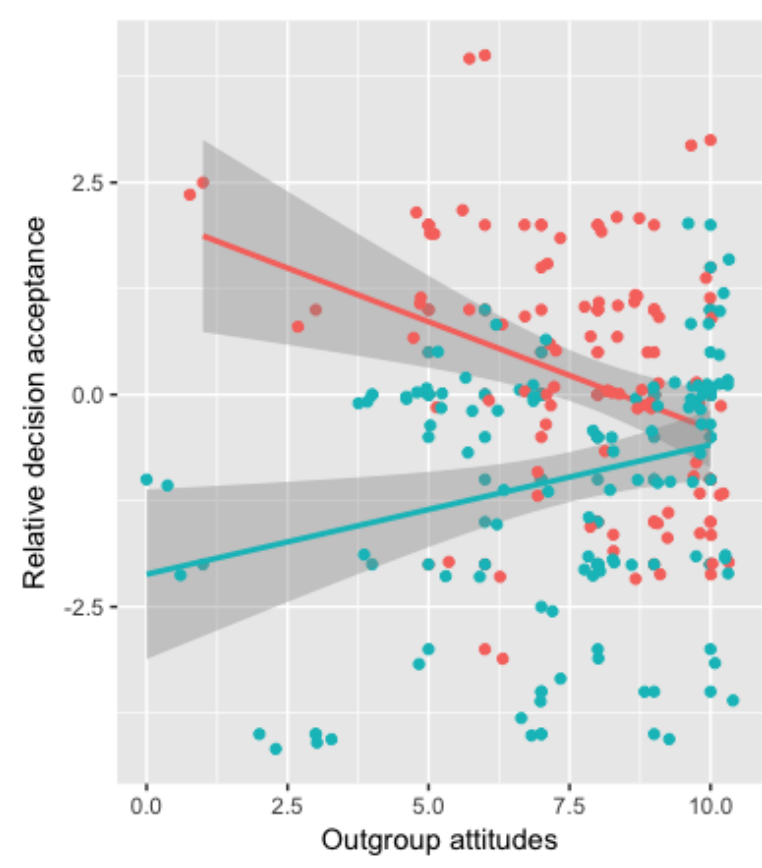

Figure 2. Scatterplot of (a) the relative perceived fairness and (b) the relative decision acceptance of decisions made about ingroup or outgroup as a function of outgroup attitudes. Shaded areas represent standard error. Note: Higher score on Y-axis indicates a preference for facilitating decisions over restrictive decisions. Points are jittered to avoid overplotting.

\section{Discussion}

The present study demonstrated that when perceptions of outgroups were relatively favourable, participants accepted ingroup and outgroup decisions relatively equally. 
However, less favourable outgroup attitudes were linked to a preference for the restrictive handling of the parade when it concerned the outgroup while producing a higher preference for facilitative decisions when they concern the ingroup. This effect was present even when controlling for ingroup identification strength and police legitimacy. While ingroup identification strength was not a significant predictor of any responses to authority decisions (whether facilitative versus restrictive or for the ingroup versus the outgroup), police legitimacy predicted responses to decisions that were restrictive in that people tended to accept these decisions more and to perceive them as fairer. Police legitimacy was not a significant predictor of responses to authority decisions that are facilitative. In other words, higher legitimacy did not necessarily grant higher compliance with the authority decisions or reduce intergroup bias.

The present findings cast doubt on whether the RMPJs in their current form can explain why fair procedures are interpreted differently in an intergroup context as a function of intergroup attitudes and how this may impact perceptions of authorities. Although aspects of RMPJs are grounded in social identity theory, the full extent of how group membership and intergroup relations shape perceptions of authority fairness, and subsequently authority legitimacy, move beyond the current theoretical scope of the RMPJs, with their characterisation of individuals' private judgements of objectively fair or unfair processes. If groups' perceptions of authority decisions are systematically based on whether the authorities act in ways that facilitate or restrict social groups, it is not clear whether authorities can represent the plethora of social groups in ways that is perceived to be legitimate by all. The present study suggests that this can be achieved more readily if the relationships between groups in the society are positive, while negative intergroup relations can sabotage authorities' ability to wield power in ways that are perceived as fair and appropriate. Authorities' behaviour towards a particular social group not only speaks to their direct relationship, but it is also embedded in the larger social contexts which includes groups that may not be directly affected by the decisions. Whether authorities are respectful 
and neutral is interpreted in the eyes of the beholder for decisions that directly impact the ingroup, but also those concerning other groups. Furthermore, RMPJs typically focus on just one social identity at the time - such as that of an employee or law-abiding citizen - rather than the multi-group structure of society. They do certainly recognise that members of different social groups may see authorities as less or more legitimate based on their identification with the authority or his or her group. In this manner, ethnic minorities and immigrants may not identify with the dominant society and, thus, be more reluctant to cooperate (Murphy \& Cherney, 2011). However, individuals may belong to multiple social groups (Jetten et al., 2015) and salience of these identities in particular contexts may influence individuals' reactions to authority decisions. Therefore, the salience of one's gender, for example, may elicit a completely different response to the same situation as the salience of ethnicity (see Shih, Pittinsky, \& Ambady, 1999). Salient identities all come with norms and behavioural prescriptions (Terry \& Hogg, 1996), some of which may guide people's reactions to authority decisions. By focusing on identification with the larger society or the immediate group that authorities represent, RMPJs do not recognise the fluidity and complexity of identities.

\section{Moving the theory forward}

The present study points towards a model of systemic authorities that incorporates the complexity of identities and the relationships between different groups in society. It places individuals and groups as the competent assessors of what is fair as opposed to passive receivers of lawfully just or unjust treatment. People actively evaluate authority decisions through the lens of group identity. Thus, our theorising points to a more dynamic processes of responding to authority decision, taking contextual variables into the account, much in line with the plea by Radburn and Stott (2018) to consider the interplay between social identity and perceptions of fairness a non-static. As such, negative attitudes towards an outgroup stemming from the past conflict can shape what it means to be a member of this 
community in light who authorities appear to serve. Given the importance of outcomes to social groups, it is important to also understand how authorities, through serving their societies, may be perceived to allow some groups to realise their goals and ambitions while simultaneously be seen by other groups as creating barriers. Moreover, these perceptions may also have spill-over consequences over time; groups which function in a hostile intergroup environment and that perceive themselves to be treated in ways that are restrictive by the authority may not only claim these actions are deeply unfair, but they may eventually also arrive at the conclusion that the authority simply does not serve people like them. Thus, while the previous research shows that authority legitimacy has few links to group-level responses to authority decisions (Leung et al., 2007), the question of how facilitative versus restrictive decisions affect how groups perceive authorities (as serving them or not) needs to be addressed using a longitudinal lens.

Not attending to the longstanding relations between racial groups, gender groups, political groups, and so forth limits the potential of RMPJs to understand the relationship between authorities and groups in the society. The RMPJs explain in detail why fair treatment is important in shaping authorities' legitimacy but focus less about how perceptions of fairness are formed in the first place and how authorities' decisions may disproportionately constrain groups or allow them to flourish. Given that groups care about outcomes, it is important to understand what function perceptions of resource distribution play in shaping perceptions of authorities, not only about own groups but also about other groups. As our findings show, reactions towards the authority decisions regarding other groups are very much influenced by how these groups are perceived in the first place. Even if resources do not play a role and what matters is that the authorities function within the boundaries of the law (Huq, Jackson, \& Trinkner, 2016), other significant questions remain to be addressed outside the current procedural justice framework. These include inquiries into why, for example, people may support authority systems that inherently do not utilise the principles of procedural justice, such as in non-democratic or authoritarian societies. 
Theoretical frameworks focusing on social groups, their goals, and norms and how these fit within the social system and other groups in the society, offering a macro-level approach, will be more suitable to address such questions.

\section{Implications for authorities}

The present research sheds light on the ways in which the support for authority decisions may be elevated in contexts of social unrest or political divide. Successful reestablishment of political bodies in countries that are currently struggling to reach political agreements is based on understanding how the legitimacy of the proposed government can be gained among all groups residing in the country. The findings of the present study suggest that positive intergroup relations can impact how authority decisions are perceived. Thus, bridging the gaps and working on the constructive relations between conflicted communities may be an important foundation to establishing political peace in other divided countries, such as Cyprus, Kosovo or Syria. There is extensive evidence that reconciliation interventions based on bringing together conflicted sides of the community can promote more harmonious intergroup relations (Pettigrew \& Tropp, 2006). Continuous community work that brings divided groups closer together can indirectly facilitate more successful deliberations at the political-level: once a political accord is reached, our results suggest that it would be more likely to gain public approval for such deal if the community relations within the society are warm than when they are icy. However, maintaining public support will also depend on the way the government facilitates or restricts resources in the light of demands imposed by groups within those territories. It is not just about disputed lands, moreover. In democratic, relatively peaceful countries, negative intergroup sentiments are related to perceptions that governments treat some groups better than others whether it is elites versus poor (Rooduijn, 2019) or immigrants versus national citizens (Urbanska \& Guimond, 2018). Those sentiments of being unjustly treated in direct comparison to other social groups may also contribute to polarised views on what is considered fair. 
The impact of RMPJs on understanding how authorities can achieve compliance has been notable and should not be neglected. Fair procedure principles are applicable in a wide range of settings from policing (Mazerolle et al., 2012), courts (Tyler \& Sevier, 2014), organisations (Blader \& Tyler, 2009; Smith, Olson, Agronick, \& Tyler, 2009) to governments (Tyler, Casper, \& Fisher, 1989). Here, however, we have argued that understanding how authorities can obtain public support is more complicated than generally implied by RMPJs because of the subjective quality of fairness judgements and the nature of intergroup relations. We argue that new theoretical advancements that are built on the basis of perceptions of fairness need to explicitly acknowledge that such perceptions are structured by intra- and intergroup relationships. Novel ways of understanding authorities, their role in the society and why some but not others comply with the system rules need to be developed more closely. Providing individuals with voice and being procedurally fair does not guarantee people's support. Research evidence on corrupt governments and divided societies may be particularly insightful here. When a government is corrupt, standing up and not obeying authorities may be normative for members within that society because such behaviours necessary to produce social change necessary to transform political system (Morselli \& Passini, 2011; Passini \& Morselli, 2009; Platow \& Hunter, 2001). A number of studies have looked at the role of procedural justice in disordered communities (Bradford, Huq, Jackson, \& Roberts, 2014; Ellison, Pino, \& Shirlow, 2012; Jonathan-Zamir \& Weisburd, 2011; Kochel, 2012), but evidence for procedural justice as an antecedent of authority legitimacy in those cases is mixed. Put differently, even subjective perceptions of fair authorities cannot grant legitimacy in conflicted intergroup settings.

\section{Limitations}

Given the directions for theoretical expansion that we have outlined, much work remains. The present study provides initial evidence for the importance of intergroup relations in shaping responses to authority decisions, but it is not without limitations. For 
example, authority decisions were presented as hypothetical and in an online scenario. It is not clear, therefore, if responses would be the same if participants witnessed how police handle the respective parades with their own eyes. It is useful to consider the consequences of accepting versus rejecting authority decisions in those scenarios in comparison to what might happen in a real-life encounter. For example, were participants invested in the outcomes of those decisions knowing that they are hypothetical? People were clearly not neutral about the outcomes of those decisions, even if they were hypothetical in nature. However, it is not clear whether the magnitude of agreement versus disagreement observed in the present research would match the magnitude of the responses in a real-life situation.

In addition to this, people tend to find authorities threatening as they have the power to constrain our freedom (Braithwaite, 2010). Given this anxious response to the presence of authority, it is less likely that those who disagree with the authority decisions in an indirect contact such as in this study would actively resist an authority decision should they find themselves in such a situation. There are no social risks to rejecting or disliking decisions in a hypothetical sense, whereby standing up to authority in such a way in a real encounter could possibly have repercussions. Thus, standing up against unjust authority may require a strong commitment as well as social support from others (van Zomeren, Spears, Fischer, \& Leach, 2004). Whether a tendency toward a collective action to protest against an unjust intergroup treatment of authorities is a variable that reflects a meaningful outcome in theory development is a question for future research.

Furthermore, we did not find support for the role of social identification in predicting the responses to authority decisions, despite the community groups' identities being salient in the experiment. The present work did not include any measures of identification with authority as suggested by Radburn and colleagues (2016). We recognise that identifying with authorities may be especially important in understanding the dynamics between authorities and the groups they represent. Future research should consider not only 
identification with the relevant ingroup, but also identification with the authority and more importantly, consider whether there are any parallels to the social identity management processes discussed in the leadership literature (Steffens et al., 2014).

\section{Conclusion}

RMPJs have transformed our understanding of the motivation behind compliance to authorities in everyday situations. However, there is a theoretical demand to expand upon these procedural justice principles to understand how authorities create cooperation in complex multigroup settings. We highlight that intergroup processes are crucial in creating a shared understanding of fairness, which impacts the relationship between authorities and groups in the societies they serve. The theoretical models addressing these issues have the potential to be extremely valuable in (re)building harmonious societies with authorities that are perceived as legitimate and citizens who accept their decisions, if they take into account the directions discussed here.

\section{References}

Blader, S. L., \& Tyler, T. R. (2009). Testing and extending the group engagement model: Linkages between social identity, procedural justice, economic outcomes, and extrarole behavior. Journal of Applied Psychology, 94, 445-464. https://doi.org/10.1037/a0013935

Boldizar, J. P., \& Messick, D. M. (1988). Intergroup fairness biases: Is ours the fairer sex? Social Justice Research, 2, 95-111. https://doi.org/10.1007/bf01048501

Bradford, B. (2014). Policing and social identity: procedural justice, inclusion and cooperation between police and public. Policing and Society, 24, 22-43. https://doi.org/10.1080/10439463.2012.724068

Bradford, B., Huq, A. Z., Jackson, J., \& Roberts, B. (2014). What price fairness when security is at stake? Police legitimacy in South Africa. Regulation \& Governance, 8, 246-268. https://doi.org/10.1111/rego.12012

Bradford, B., Murphy, K., \& Jackson, J. (2014). Officers as mirrors: Policing, procedural justice and the (re)production of social identity. British Journal of Criminology, 54, 527550. https://doi.org/10.1093/bjc/azu021

Braithwaite, V. (2010). Defiance in taxation and governance: Resisting and dismissing authority in a democracy. Cheltenham, UK: Edward Elgar Publishing. 
Davis, J. A. (1959). A formal interpretation of the theory of relative deprivation. Sociometry, 22, 280-296. https://doi.org/10.2307/2786046

Doosje, B., Ellemers, N., \& Spears, R. (1995). Perceived intragroup variability as a function of group status and identification. Journal of Experimental Social Psychology, 31, 410436. https://doi.org/10.1006/jesp.1995.1018

Dubé, L., \& Guimond, S. (1986). Relative deprivation and social protest: The personal-group issue. In J. M. Olson, C. P. Herman, \& M. P. Zanna (Eds.), Relative deprivation and social comparison: The Ontario Symposium (pp. 201-212). Hillsdale, NJ: Lawrence Erlbaum Associates.

Ellemers, N., Rijswijk, W., Bruins, J. A., \& Gilder, D. D. (1998). Group commitment as a moderator of attributional and behavioural responses to power use. European Journal of Social Psychology, 28, 555-573. https://doi.org/10.1002/(sici)10990992(199807/08)28:4<555::aid-ejsp879>3.0.co;2-w

Ellison, G., Pino, N. W., \& Shirlow, P. (2012). Assessing the determinants of public confidence in the police: A case study of a post-conflict community in Northern Ireland. Criminology and Criminal Justice, 13, 552-576. https://doi.org/10.1177/1748895812462597

Epp, C. R., Maynard-Moody, S., \& Haider-Markel, D. P. (2014). Pulled over: How police stops define race and citizenship. London, UK: The University of Chicago Press.

Folger, R. (1977). Distributive and procedural justice: Combined impact of voice and improvement on experienced inequity. Journal of Personality and Social Psychology, 35, 108-119. https://doi.org/10.1037//0022-3514.35.2.108

French, J. R. P., \& Raven, B. (1959). The bases of social power. In D. Cartwright (Ed.), Studies in Social Power (pp. 259-269). Ann Arbor, MI: Institute for Social Research.

Giessner, S. R., Viki, G. T., Otten, S., Terry, D. J., \& Tauber, S. (2006). The challenge of merging: Merger patterns, premerger status and merger support. Personality and Social Psychology Bulletin, 32, 339-352. https://doi.org/10.1177/0146167205282151

Guimond, S., \& Dambrun, M. (2002). When prosperity breeds intergroup hostility: The effects of relative deprivation and relative gratification on prejudice. Personality and Social Psychology Bulletin, 28, 900-912. https://doi.org/10.1177/014616720202800704

Haddock, G., Zanna, M. P., \& Esses, V. M. (1993). Assessing the structure of prejudicial attitudes: The case of attitudes toward homosexsuals. Journal of Personality and Social Psychology, 65, 1105-1118. https://doi.org/10.1037/0022-3514.65.6.1105

Halabi, S., Statman, Y., \& Dovidio, J. F. (2015). Attributions of responsibility and punishment for ingroup and outgroup members: The role of just world beliefs. Group Processes \& Intergroup Relations, 18, 104-115. https://doi.org/10.1177/1368430214546067

Hauenstein, N. M. A., McGonigle, T., \& Flinder, S. W. (2001). A meta-analysis of the relationship between procedural justice and distributive justice: Implications for justice research. Employee Responsibilities and Rights Journal, 13, 39-56.

https://doi.org/10.1023/A:1014482124497 
Hayes, A. F. (2012). PROCESS: A versatile computational tool for observed variable mediation, moderation, and conditional process modeling. Retrieved from http://www.afhayes.com/

Hildreth, J. A. D., Moore, D. A., \& Blader, S. L. (2014). Revisiting the instrumentality of voice: Having voice in the process makes people think they will get what they want. Social Justice Research, 27, 209-230. https://doi.org/10.1007/s11211-014-0211-9

Huq, A. Z., Jackson, J., \& Trinkner, R. J. (2016). Legitimating practices: Revisiting the predicates of police legitimacy. British Journal of Criminology, 1-27. https://doi.org/10.1093/bjc/azw037

Jetten, J., Branscombe, N. R., Haslam, S. A., Haslam, C., Haslam, C., Cruwys, T., ... Zhang, A. (2015). Having a lot of a good thing: Multiple important group memberships as a source of self-esteem. Plos One, 10, 1-29. https://doi.org/10.1371/journal.pone.0131035

Jonathan-Zamir, T., \& Weisburd, D. (2011). The effects of security threats on antecedents of police legitimacy: Findings from a quasi-experiment in Israel. Journal of Research in Crime and Delinquency, 50, 3-32. https://doi.org/10.1177/0022427811418002

Kochel, T. R. (2012). Can police legitimacy promote collective efficacy? Justice Quarterly, 29, 384-419. https://doi.org/10.1080/07418825.2011.561805

Leach, C. W., \& Spears, R. (2009). Dejection at in-group defeat and schadenfreude toward second- and third-party out-groups. Emotion, 9, 659-665.

https://doi.org/10.1037/a0016815

Leung, K., Tong, K., \& Lind, E. A. (2007). Realpolitik versus fair process: Moderating effects of group identification on acceptance of political decisions. Journal of Personality and Social Psychology, 92, 476-489. https://doi.org/10.1037/0022-3514.92.3.476

Leventhal, G. S. (1980). What should be done with equity theory? New approaches to the study of fairness in social relationships. In K. J. Gergen, M. S. Greenberg, \& R. H. Willis (Eds.), Social exchange: Advances in theory and research (pp. 27-55). New York, NY: Plenum Press.

Lind, E. A., Kanfer, R., \& Earley, P. C. (1990). Voice, control, and procedural justice: Instrumental and noninstrumental concerns in fairness judgments. Journal of Personality and Social Psychology, 59, 952-959. https://doi.org/10.1037//00223514.59.5.952

Lind, E. A., \& Tyler, T. R. (1988). The social psychology of procedural justice. New York, NY: Plenum Press.

Mazerolle, L., Bennett, S., Antrobus, E., \& Eggins, E. (2012). Procedural justice, routine encounters and citizen perceptions of police: main findings from the Queensland Community Engagement Trial (QCET). Journal of Experimental Criminology, 8, 343367. https://doi.org/10.1007/s11292-012-9160-1

Mazerolle, L., Bennett, S., Davis, J., Sargeant, E., \& Manning, M. (2013). Procedural justice and police legitimacy: A systematic review of the research evidence. Journal of Experimental Criminology, 9, 245-274. https://doi.org/10.1007/s11292-013-9175-2 
McVeigh, R., \& Rolston, B. (2007). From Good Friday to good relations: Sectarianism, racism and the Northern Ireland state. Race \& Class, 48, 1-23. https://doi.org/10.1177/0306396807077009

Messick, D. M., Bloom, S., Boldizar, J. P., \& Samuelson, C. D. (1985). Why we are fairer than others. Journal of Experimental Social Psychology, 21, 480-500. https://doi.org/10.1016/0022-1031(85)90031-9

Morselli, D., \& Passini, S. (2011). New perspectives on the study of the authority relationship: Integrating individual and societal level research. Journal for the Theory of Social Behaviour, 41, 291-307. https://doi.org/10.1111/j.1468-5914.2011.00459.x

Murphy, K., \& Cherney, A. (2011). Fostering cooperation with the police: How do ethnic minorities in Australia respond to procedural justice-based policing? Australian \& New Zealand Journal of Criminology, 44, 235-257. https://doi.org/10.1177/0004865811405260

Nolan, P., \& Bryan, D. (2016). Flags: Towards a new understanding. Belfast, UK.

Nolan, P., Bryan, D., Dwyer, C., Hayward, K., Radford, K., \& Shirlow, P. (2014). The flag dispute: Anatomy of a protest. Belfast, UK.

Passini, S., \& Morselli, D. (2009). Authority relationships between obedience and disobedience. New Ideas in Psychology, 27, 96-106. https://doi.org/10.1016/j.newideapsych.2008.06.001

Peate, V. G., Platow, M. J., \& Eggins, R. A. (2008). Collective voice and support for social protest among indigenous and non-indigenous Australians: Considering the role of procedural fairness in an intergroup conflict of interest. Australian Journal of Psychology, 60, 175-185. https://doi.org/10.1080/00049530701867847

Pehrson, S., Devaney, L., Blaylock, D., \& Bryan, D. (2017). Beyond group engagement: Multiple pathways from encounters with the police to cooperation and compliance in Northern Ireland. PLOS ONE. https://doi.org/https://doi.org/10.1371/journal.pone.0184436

Pettigrew, T. F., Christ, O., Wagner, U., Meertens, R. W., van Dick, R., \& Zick, A. (2008). Relative deprivation and intergroup prejudice. Journal of Social Issues, 64, 385-401. Retrieved from http://doi.wiley.com/10.1111/j.1540-4560.2008.00567.x

Pettigrew, T. F., \& Tropp, L. R. (2006). A meta-analytic test of intergroup contact theory. Journal of Personality and Social Psychology, 90(5), 751-783. https://doi.org/10.1037/0022-3514.90.5.751

Platow, M. J., Filardo, F., Troselj, L., Grace, D. M., \& Ryan, M. K. (2006). Non-instrumental voice and extra-role behaviour. European Journal of Social Psychology, 36, 135-146. https://doi.org/10.1002/ejsp.293

Platow, M. J., Grace, D. M., Wilson, N., Burton, D., \& Wilson, A. (2008). Psychological group memberships as outcomes of resource distributions. European Journal of Social Psychology, 38, 836-851. https://doi.org/10.1002/ejsp.489

Platow, M. J., Hoar, S., Reid, S. A., \& Harley, K. (1997). Endorsement of distributively fair 
and unfair leaders in interpersonal and intergroup situations. European Journal of Social Psychology, 27, 465-494. https://doi.org/10.1002/(sici)1099-

0992(199707)27:4<465::aid-ejsp817>3.0.co;2-8

Platow, M. J., \& Hunter, J. A. (2001). Realistic intergroup conflict: Prejudice, power, and protest. In M. Augoustinos \& K. J. Reynolds (Eds.), Understanding prejudice, racism, and social conflict (pp. 195-212). London, UK: Sage Publications.

Platow, M. J., Hunter, J. A., Branscombe, N. R., \& Grace, D. M. (2014). Social creativity in Olympic medal counts: Observing the expression of ethnocentric fairness. Social Justice Research, 27, 283-304. https://doi.org/10.1007/s11211-014-0219-1

Platow, M. J., \& O'Brien, L. V. (2009). Distributive and procedural justice: Acceptability as solutions to social dilemmas. In A. Kakanowski \& M. Narusevich (Eds.), Handbook of Social Justice (pp. 103-124). New York, NY: Nova Science Publishers.

Platow, M. J., Reid, S. A., \& Andrew, S. (1998). Leadership endorsement: The role of distributive and procedural behavior in interpersonal and intergroup contexts. Group Processes \& Intergroup Relations, 1, 35-47. https://doi.org/10.1177/1368430298011004

Platow, M. J., Wezel, M., \& Nolan, M. (2003). The importance of social identity and selfcategorization processes for creating and responding to fairness. In S. A. Haslam, D. van Knippenberg, M. J. Platow, \& N. Ellemers (Eds.), Social identity at work: Developing theory for organizational practice (pp. 261-276). New York, NY: Psychology Press.

Radburn, M., \& Stott, C. (2018). The social psychological processes of "procedural justice": Concepts, critiques and opportunities. Criminology and Criminal Justice. https://doi.org/10.1177/1748895818780200

Radburn, M., Stott, C., Bradford, B., \& Robinson, M. (2016). When is policing fair? Groups, identity and judgements of the procedural justice of coercive crowd policing. Policing and Society. https://doi.org/10.1080/10439463.2016.1234470

Ramirez, M. D. (2008). Procedural perceptions and support for the U.S. Supreme Court. Political Psychology, 29, 675-698. https://doi.org/10.1111/j.1467-9221.2008.00660.x

Reisig, M. D., Bratton, J., \& Gertz, M. G. (2007). The construct validity and refinement of process-based policing measures. Criminal Justice and Behavior, 34, 1005-1028. https://doi.org/10.1177/0093854807301275

Rooduijn, M. (2019). State of the field: How to study populism and adjacent topics? A plea for both more and less focus. European Journal of Political Research, 58, 362-372. https://doi.org/10.1111/1475-6765.12314

Runciman, W. G. (1966). Relative deprivation and social justice. London, UK: Routledge.

Sargeant, E., Antrobus, E., Murphy, K., Bennett, S., \& Mazerolle, L. (2014). Social identity and procedural justice in police encounters with the public: Results from a randomised controlled trial. Policing and Society, 11, 1-15.

https://doi.org/10.1080/10439463.2014.989159 
Shayegh, J., Drury, J., \& Stevenson, C. (2017). Listen to the band! How sound can realize group identity and enact intergroup domination. British Journal of Social Psychology, 56(1), 181-196. https://doi.org/10.1111/bjso.12175

Shih, M., Pittinsky, T. L., \& Ambady, N. (1999). Stereotype susceptibility: Identity salience and shifts in quantitative performance. Psychological Science, 10, 80-83. https://doi.org/10.1111/1467-9280.00111

Skarlicki, D. P., \& Kulik, C. T. (2004). Third-party reactions to employee (mis)treatment: A justice perspective. Research in Organizational Behaviour, 26, 183-229. https://doi.org/10.1007/s13398-014-0173-7.2

Smith, H. J., Olson, G., Agronick, G., \& Tyler, T. R. (2009). Everyday interactions with university authorities: Authority treatment quality, outcome favorability and first-year students' university adjustment. Group Processes \& Intergroup Relations, 12, 209-226. https://doi.org/10.1177/1368430208101057

Steffens, N. K., Haslam, S. A., Reicher, S. D., Platow, M. J., Fransen, K., Yang, J., ... Boen, F. (2014). Leadership as social identity management: Introducing the Identity Leadership Inventory (ILI) to assess and validate a four-dimensional model. Leadership Quarterly, 25, 1001-1024. https://doi.org/10.1016/j.leaqua.2014.05.002

Sugawara, I., \& Huo, Y. J. (1994). Disputes in Japan: A cross-cultural test of the procedural justice model. Social Justice Research, 7, 129-144. https://doi.org/10.1007/bf02337295

Sunshine, J., \& Tyler, T. R. (2003). The role of procedural justice and legitimacy in shaping public support for policing. Law \& Society Review, 37, 513-548.

https://doi.org/10.1111/1540-5893.3703002

Tajfel, H., \& Turner, J. C. (1979). An integrative theory of intergroup conflict. In W. G. Austin \& S. Worchel (Eds.), The social psychology of intergroup relations (pp. 33-47). Monterey, CA: Brooks/Cole.

Terry, D. J., \& Hogg, M. A. (1996). Group norms and the attitude- behavior relationship: A role for group identification. Personality and Social Psychology Bulletin, 22, 776-793. https://doi.org/10.1177/0146167296228002

The Parades Commission. (2015). Annual report and financial statements for the year ended 31 March 2015. Retrieved from https://www.paradescommission.org/getmedia/13073306-be1b-4787-ad3a508d2f507e57/NorthernIrelandParadesCommission.aspx

Thibaut, J., \& Walker, L. (1975). Procedural justice: A psychological analysis. Hillsdale, NJ: Erlbaum.

Turner, J. C. (1975). Social comparison and social identity: Some prospects for intergroup behavior. European Journal of Social Psychology, 5, 5-34.

https://doi.org/10.1002/ejsp.2420050102

Turner, J. C., Hogg, M. A., Oakes, P. J., Reicher, S. D., \& Wetherell, M. S. (1987).

Rediscovering the social group: A self-categorisation theory. Oxford, UK: Blackwell.

Tyler, T. R. (1997). The psychology of legitimacy: A relational perspective on voluntary 
deference to authorities. Personality and Social Psychology Review, 1, 323-345. https://doi.org/10.1207/s15327957pspr0104_4

Tyler, T. R. (2006). Why people obey the law (2nd ed.). New Haven, CT: Yale University Press.

Tyler, T. R., Casper, J. D., \& Fisher, B. (1989). Maintaining allegiance toward political authorities: The role of prior attitudes and the use of fair procedures. American Journal of Political Science, 33, 629-652. https://doi.org/10.2307/2111066

Tyler, T. R., Degoey, P., \& Smith, H. J. (1996). Understanding why the justice of group procedures matters: A test of the psychological dynamics of the group-value model. Journal of Personality and Social Psychology, 70, 913-930.

https://doi.org/10.1037//0022-3514.70.5.913

Tyler, T. R., \& Huo, Y. J. (2002). Trust in the law: Encouraging public cooperation with the police and courts. New York, NY: Russell Sage.

Tyler, T. R., \& Sevier, J. (2014). How do the courts create popular legitimacy? The role of establishing the truth, punishing justly, and/or acting through just procedures. Albany Law Review, 77, 1095-1138.

Urbanska, K., \& Guimond, S. (2018). Swaying to the extreme: Group relative deprivation predicts voting for an extreme right party in the French presidential election. International Review of Social Psychology, 31(1). https://doi.org/10.5334/irsp.201

Urbanska, K., McKeown, S., \& Taylor, L. K. (2019). From injustice to action: The role of empathy and perceived fairness to address inequality via victim compensation. Journal of Experimental Social Psychology, 82(February 2018), 129-140.

https://doi.org/10.1016/j.jesp.2019.01.010

van den Bos, K., \& Lind, E. A. (2001). The psychology of own versus others' treatment: Selforiented and other-oriented effects on perceptions of procedural justice. Personality and Social Psychology Bulletin, 27, 1324-1333.

https://doi.org/10.1177/01461672012710008

van Prooijen, J. W., \& Zwenk, F. (2009). Self-construal level and voice procedures: The individual self as psychological basis for procedural fairness effects. Journal of Experimental Social Psychology, 45, 392-397. https://doi.org/10.1016/j.jesp.2008.10.008

van Zomeren, M., Spears, R., Fischer, A. H., \& Leach, C. W. (2004). Put your money where your mouth is! Explaining collective action tendencies through group-based anger and group efficacy. Journal of Personality and Social Psychology, 87, 649-664. https://doi.org/10.1037/0022-3514.87.5.649

Visschers, V. H. M., \& Siegrist, M. (2012). Fair play in energy policy decisions: Procedural fairness, outcome fairness and acceptance of the decision to rebuild nuclear power plants. Energy Policy, 46, 292-300. https://doi.org/10.1016/j.enpol.2012.03.062

Walker, I., \& Pettigrew, T. F. (1984). Relative deprivation theory: An overview and conceptual critique. British Journal of Social Psychology, 23, 301-310. https://doi.org/10.1111/j.2044-8309.1984.tb00645.x 
Wenzel, M., \& Jobling, P. (2006). Legitimacy of regulatory authorities as a function of inclusive identification and power over ingroups and outgroups. European Journal of Social Psychology, 36, 239-258. https://doi.org/10.1002/ejsp.298

Whyte, J. (1991). Interpreting Northern Ireland. Oxford, UK: Oxford University Press. 